\title{
Electrochemical Data on the Effect of Extreme Temperatures on 2101 Duplex Steel Corrosion Performance in Chloride-Sulphate Environment
}

\author{
ROLAND TOLULOPE LOTO \\ Department of Mechanical Engineering, Covenant University, Ota, Ogun State, Nigeria. \\ ${ }^{*}$ Corresponding author E-mail: tolu.loto@ gmail.com \\ http://dx.doi.org/10.13005/ojc/350204
}

(Received: November 09, 2018; Accepted: March 12, 2019)

\begin{abstract}
The detrimental effect of heat treatment processes at $1200^{\circ} \mathrm{C}$ on 2101 duplex stainless steel was studied in $2 \mathrm{M} \mathrm{H}_{2} \mathrm{SO}_{4} / 0 \%-1.75 \% \mathrm{NaCl}$ by potentiodynamic polarization, open circuit potential measurement and optical microscopy analysis. Result showed the processes increased the corrosion susceptibility of the duplex alloy with maximum corrosion rate value of $11.3 \mathrm{~mm} / \mathrm{y}$ at $0.5 \% \mathrm{NaCl}$ for the annealed steel (A2101ST), followed by quenched steel (Q2101ST) with corrosion rate value of $9.03 \mathrm{~mm} / \mathrm{y}$. These values were significantly lower than the peak corrosion rate of the as received steel (ASR2101ST) at $5.785 \mathrm{~mm} / \mathrm{y}$. The corrosion rate of all the duplex steels generally decreased beyond $0.5 \% \mathrm{NaCl}$. ASR2101ST sustained it passivation characteristics till $1.75 \% \mathrm{NaCl}$ due to the resilience of its oxide protective film while the passive film of Q2101ST and A2101ST were completely destroyed due to changes in the metallurgical structure of the heat treated duplex steels. While the surface of ASR2101ST mildly deteriorated, severe intergranular and pitting corrosion was observed on Q2101ST and the surface of A2101ST was marginally pitted in the presence of $\mathrm{SO}_{4}{ }_{4}^{2-}$ ions. In $\mathrm{Cl} / \mathrm{SO}_{4}{ }^{2-}$ ion solution ASR2101ST showed an etched morphology with ferrite and austenite phases appearing in addition to superficial pitting. Q2101ST and A2101ST were severely deteriorated in the solution.
\end{abstract}

Keywords: Pitting, Corrosion, Steel, Microstructure.

\section{INTRODUCTION}

Stainless steels have wide spread applications across all industries due to their excellent physical, mechanical, economical and corrosion resistant properties ${ }^{1}$. Duplex stainless steel combines their low nickel content with its high mechanical strength making them a cost effective counterpart to austenitic stainless steel grades.
They consist of a ferrite and austenite phase microstructure coexisting together as a result it embodies the characteristics of both ferrite having high strength and durability, and the austenite which is known to have excellent corrosion resistance ${ }^{2-4}$. The dual nature of duplex steels enables its versatile application as material of construction for pipeline, pressure vessels and storage tanks, in sea water, well design and in environments where corrosion

This is an Open Access article licensed under a Creative Commons license: Attribution 4.0 International (CC- BY). Published by Oriental Scientific Publishing Company @ 2018 
and wear resistance are high priorities ${ }^{5-9}$. Their dual-phase microstructure is highly dependent on their nominal (wt.\%) composition and heat treatment history. Heat treatment is necessary for duplex stainless steel (DSS) to remove or dissolve intermetallic phases, to remove segregation and to relieve any residual thermal stress in DSS, which may be formed during production processes. Heat treatment processes have mixed effect on duplex stainless steel with respect to temperature range, duration and cooling rates. Though the processes are commonly associated with enhancing strength properties ferrous alloys, it is also utilized in altering manufacturability objectives to improve ductility, machining and formability after plastic deformation processes Previous research has shown that quenching heat treatment improves the corrosion resistance of 420 martensitic stainless steel by $60 \%$ on 316 steel, there is no significant improvement in the corrosion resistance of the steel. The presence of alloying elements such as $\mathrm{Cr}, \mathrm{Ni}$ and Mo impart excellent corrosion resistant properties on duplex steel nevertheless when subject to extreme heat treatment processes, several harmful precipitates such as carbides, nitrides and intermetallic phase's forms resulting in weak resistance to intergranular crack and pit formation on the stee $1^{10,11}$. This research aims to assess and document the effect of extreme temperatures on the corrosion resistance of 2101 duplex stainless steel in chloride sulphate environment.

\section{EXPERIMENTAL}

2101 duplex stainless steel (2101ST) obtained commercially is the subject steel alloy under study. The nominal wt. \% composition of the steel was determined at the Materials Characterization Laboratory, Department of Mechanical Engineering, Covenant, Ogun State, Nigeria. The composition results are depicted in Table 1. The duplex alloys were cut and sectioned to dimensions with exposed surface area of $1.27 \mathrm{~cm}^{2}$. Some of the duplex alloy samples underwent quenching (Q2101ST) and annealing (A2101ST) heat treatment process in a muffle furnace after heating the steel to $1200^{\circ} \mathrm{C}$ and sustaining them at the particular temperature for 30 minutes. The annealed duplex alloy was allowed to cool naturally in air while the quenched 301 SS was rapidly cooled in distilled water to achieve the required metallurgical structure. The temperature was maintained with a regulator at an accuracy $\pm 10^{\circ} \mathrm{C}$ linked with a thermocouple (K-Type) to achieve the required temperature. They as received (ASR2101ST), quenched and annealed duplex samples were subsequently prepared through metallographic technique. Abrasive silicon carbide papers with grits of $60,120,220,320,600$, 800 and 1000 was used to ground the specimens after which polishing was done with diamond liquid paste to $6 \mu \mathrm{m}$ before washing with distilled water and acetone for potentiodynamic polarization and open circuit potential measurement. Recrystallized sodium chloride obtained from Titan Biotech, India was formulated in proportional concentrations of $0 \%$, $0.25 \%, 0.5 \%, 0.75 \%, 1 \%, 1.25 \%, 1.5 \%$, and $1.75 \%$ in $200 \mathrm{~mL}$ of $2 \mathrm{M} \mathrm{H}_{2} \mathrm{SO}_{4}$ solution, prepared from analar grade of $\mathrm{H}_{2} \mathrm{SO}_{4}$ acid (98\%) with distilled water.

Table 1: Percentage Nominal Composition of 2101ST

\begin{tabular}{lccccccccc}
\hline Element Symbol & $\mathrm{Mo}$ & $\mathrm{Si}$ & $\mathrm{Ni}$ & $\mathrm{Cr}$ & $\mathrm{Mn}$ & $\mathrm{P}$ & $\mathrm{N}$ & $\mathrm{C}$ & $\mathrm{Fe}$ \\
\hline \% Composition & 0.4 & 1 & 1.8 & 22.8 & 4 & 0.04 & 0.2 & 0.03 & 69.7 \\
$2101 \mathrm{STa}$ & & & & & & & & & \\
\hline
\end{tabular}

Potentiodynamic polarization tests was performed on ASR2101ST, Q2101ST and A2101ST at $37^{\circ} \mathrm{C}$ ambient temperature with a three electrode cell (platinum counter electrodes, $\mathrm{Ag} / \mathrm{AgCl}$ reference electrodes and resin embedded 2101ST electrodes) containing $200 \mathrm{~mL}$ of the $2 \mathrm{M} \mathrm{H}_{2} \mathrm{SO}_{4}$ at specific $\mathrm{NaCl}$ concentrations media and connected to Digi-Ivy 2311 electrochemical workstation. Polarization plots were produced at scan rate of $0.0015 \mathrm{~V} / \mathrm{s}$ from $-1.5 \mathrm{~V}$ and $+1 \mathrm{~V}$ set potentials. The corrosion current density, $\mathrm{C}_{\mathrm{d}}$ $\left(\mathrm{A} / \mathrm{cm}^{2}\right)$ and corrosion potential, $\mathrm{C}_{\mathrm{p}}(\mathrm{V})$ values were obtained from the polarization plots through Tafel extrapolation method. Corrosion rate, $\mathrm{C}_{\mathrm{R}}(\mathrm{mm} / \mathrm{y})$ and inhibition efficiency, $\eta(\%)$ were determined from the following mathematical relationship;

$C_{\mathrm{R}}=\frac{0.00327 \times C_{\mathrm{d}} \times E_{\mathrm{q}}}{D}$

$D$ is the density in $\left(\mathrm{g} / \mathrm{cm}^{3}\right)$; Eq is the metal alloy equivalent weight $(\mathrm{g}) .0 .00327$ is the constant for corrosion rate. Open circuit potential measurement (OCP) was performed at $0.05 \mathrm{~V} / \mathrm{s}$ step potential for 2000 s to study the thermodynamic stability of the alloys at rest potentials. Micro analytical images of the duplex alloys surface configuration were studied before and after electrochemical degradation with Omax trinocular metallurgical microscope using ToupCam analytical software. 


\section{RESULT AND DISCUSSION}

\section{Potentiodynamic polarization test}

The corrosion polarization behavior of ASR2101ST, Q2101ST and A2101ST duplex alloy specimens are shown on the anodic-cathodic polarization plots depicted in Figs. 1-3. Results of the polarization test are shown in Table 2. ASR2101ST generally had the lowest corrosion rate coupled with a proportionate value of corrosion current density. Its corrosion rate values increased with rise in chloride concentration and peaked at $0.5 \% \mathrm{NaCl}$, thereafter a progressive decrease was observed till $1.75 \%$. The same phenomenon occurred for Q2010ST and A2101ST at relatively higher corrosion rates; however A2101ST had the highest corrosion rate values signifying low corrosion resistance due to a number of factors such as degradation resulting from precipitation due to depletion of corrosion-resisting elements ( $\mathrm{Cr}, \mathrm{Ni}, \mathrm{Mo}$ etc.) within the alloy substrate and intermetallic rearrangements. The corrosion behavior 2101ST duplex steel is subject to the state of its microstructural properties which undergoes significant changes due to phase transformations during heat treatment. Observation of the corrosion potentials of ASR2101ST and Q2101ST showed active passive behavior between anodic and cathodic values as a result of the counterbalancing action of the redox electrochemical processes occurring on the alloy surface. The potential values for A2101ST appear to be comparatively more electronegative. This is associated with the weakening of the passive film and localized corrosion reactions on the metal alloy surface, hence its relatively higher corrosion rate values.

Study of the anodic portion of the polarization plots of the duplex alloy specimens (Figs. 1-3) before passivation shows a progressive increase in metastable pitting region with respect to $\mathrm{Cl}$ - ion concentration due to initiation of unstable transient corrosion pits. Pit growth during this period is subject to diffusion of metallic cations from the initiated corrosion pit. The metastable pitting current decreased before the formation of the protective oxide film to a constant passivity current density and achieving relative stability. Extended increase in the anodic portion of all the polarization plots was observed beyond $0.5 \% \mathrm{NaCl}$ concentration $(0.75 \%-1.25 \% \mathrm{NaCl})$ as a result of increased oxidation reactions of the duplex alloy due to higher $\mathrm{Cl}$ - ion concentration which is responsible for higher metastable pitting nucleation rate. This in effect reduced the passivation range of the alloys, hence their corrosion resistance properties before breakdown at the transpassive region of the plot. At $1.25 \% \mathrm{NaCl}, \mathrm{Q} 2101 \mathrm{ST}$ and A2101ST had significantly reduced passivation range due to active corrosion reactions before passivation when compared to ASR2101ST. The decrease in passivation range of the two aforementioned duplex alloys decreased further at $1.5 \% \mathrm{NaCl}$ due to delayed passivation of the alloys, where as ASR2101ST continued to passivate at lower corrosion potentials. At $1.75 \% \mathrm{NaCl}$ concentration, Q2101ST and A2101ST duplex alloys where unable to passivate throughout the scanned potentials due to destruction of their passive film at the stated chloride concentration. However ASR2101 still passivated at higher corrosion potentials $(-0.94 \mathrm{~V})$ due to the debilitating action of the chloride ions. Variation in $\mathrm{Cl}$ - ion concentration had minimal effect on the pitting potential of the duplex alloys; however a significant increase in pitting corrosion current occurred before breakdown of the alloys.

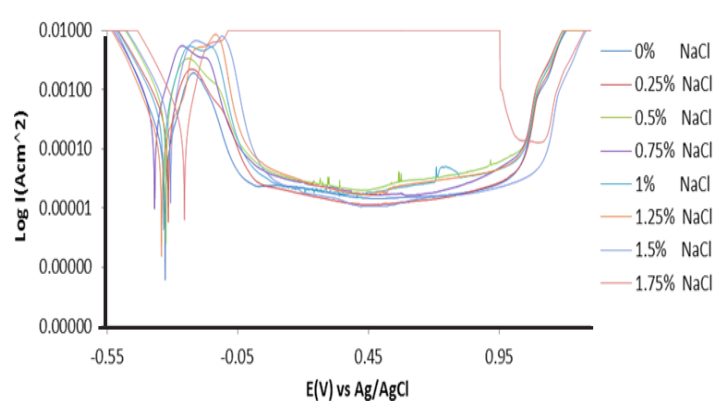

Fig. 1. Potentiodynamic polarization plots of ASR2101ST corrosion in $2 \mathrm{M} \mathrm{H}_{2} \mathrm{SO}_{4} / 0 \%-1.25 \% \mathrm{NaCl}$ solution

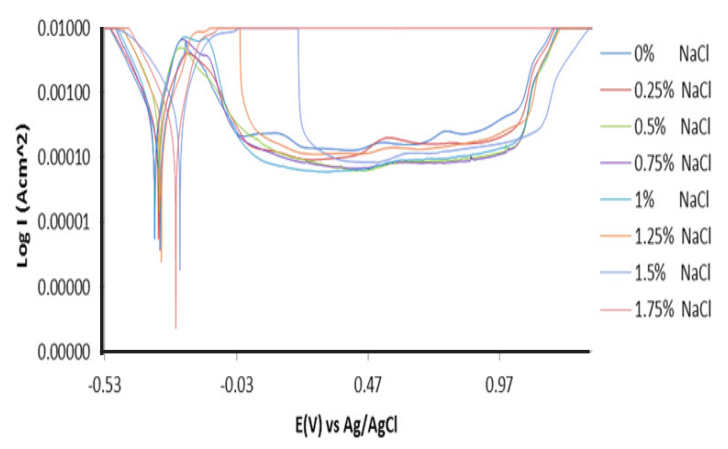

Fig. 2. Potentiodynamic polarization plots of Q2101ST corrosion in $2 \mathrm{M} \mathrm{H}_{2} \mathrm{SO}_{4} / 0 \%-1.25 \% \mathrm{NaCl}$ solution 


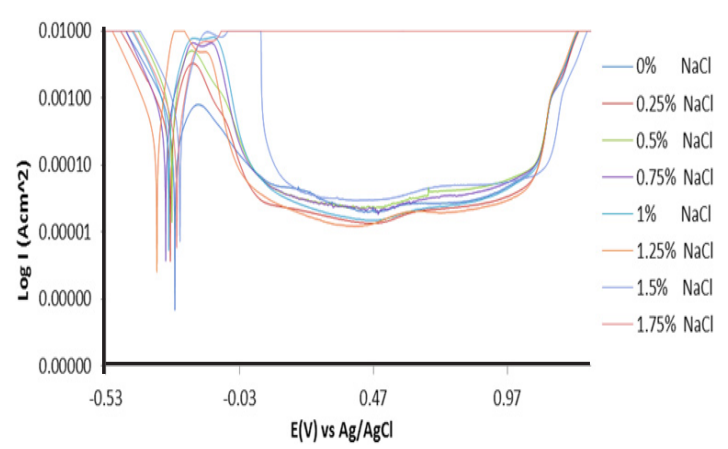

Fig. 3. Potentiodynamic polarization plots of A2101ST corrosion in $2 \mathrm{M} \mathrm{H}_{2} \mathrm{SO}_{4} / 0 \%-1.25 \% \mathrm{NaCl}$ solution

\section{Optical microscopy analysis}

Optical microscopic images (mag. $\times 40$ and x100) of ASR2101ST, Q2101ST and A2101ST duplex alloys before corrosion, and after corrosion from $2 \mathrm{M}$ $\mathrm{H}_{2} \mathrm{SO}_{4}$ and $2 \mathrm{M} \mathrm{H}_{2} \mathrm{SO}_{4} / 1.75 \% \mathrm{NaCl}$ are shown from Fig. 4(a) to 6(c). The optical images before corrosion [Fig. 4(a) - (c)] are generally similar, though serrated edges are more visible on the quenched and annealed steel. The optical image of ASR2101ST [Fig. 5(a)] showed the presence of very few corrosion pits due to the action of $\mathrm{SO}_{4}{ }_{4}^{2-}$ ions without chlorides; however the extent of morphological damage is much more visible on Q210ST alloy [Fig. 5(b)]

Table 2: Polarization data on ASR2101ST, Q2101ST and A2101ST corrosion in $2 \mathrm{M} \mathrm{H}_{2} \mathrm{SO}_{4} / 0 \%-1.25 \% \mathrm{NaCl}$ solution

ASR2101ST

Sample $\mathrm{NaCl}$ Corrosion Corrosion Corrosion Current Corrosion Polarization Cathodic Tafel Anodic Tafel Conc. (\%) Rate (mm/y) Current (A) Density $\left(\mathrm{A} / \mathrm{cm}^{2}\right) \quad$ Potential $(\mathrm{V}) \quad$ Resistance, Slope, Bc Slope, Ba

Q2101ST
Sample $\mathrm{NaCl}$ Corrosion Corrosion Corrosion Current Corrosion Polarization Cathodic Tafel Anodic Tafel
Conc. (\%) Rate $(\mathrm{mm} / \mathrm{y}) \quad$ Current $(\mathrm{A}) \quad$ Density $\left(\mathrm{A} / \mathrm{cm}^{2}\right) \quad$ Potential $(\mathrm{V}) \quad$ Resistance, Slope, Bc Slope, Ba

\begin{tabular}{|c|c|c|c|c|c|c|c|c|}
\hline A & 0 & 2.919 & 3.45E-04 & 2.71E-04 & -0.321 & 74.56 & -9.428 & 9.818 \\
\hline B & 0.25 & 3.637 & $4.29 \mathrm{E}-04$ & 3.38E-04 & -0.327 & 53.80 & -8.252 & 8.949 \\
\hline C & 0.5 & 9.030 & 1.07E-03 & 8.39E-04 & -0.324 & 24.11 & -8.588 & 2.191 \\
\hline D & 0.75 & 4.441 & $5.24 \mathrm{E}-04$ & 4.13E-04 & -0.341 & 49.01 & -9.969 & 14.540 \\
\hline E & 1 & 4.465 & 5.27E-04 & 4.15E-04 & -0.341 & 39.71 & -9.613 & 12.900 \\
\hline $\mathrm{F}$ & 1.25 & 3.202 & 3.78E-04 & $2.98 \mathrm{E}-04$ & -0.320 & 67.98 & -10.230 & 12.470 \\
\hline $\mathrm{G}$ & 1.5 & 3.287 & 3.88E-04 & 3.06E-04 & -0.245 & 61.34 & -7.441 & 9.145 \\
\hline $\mathrm{H}$ & 1.75 & 3.530 & 4.17E-04 & 3.28E-04 & -0.261 & 54.65 & -9.241 & 13.190 \\
\hline \multicolumn{9}{|c|}{ A2101ST } \\
\hline Sample & $\begin{array}{c}\mathrm{NaCl} \\
\text { Conc. (\%) }\end{array}$ & $\begin{array}{l}\text { Corrosion } \\
\text { Rate }(\mathrm{mm} / \mathrm{y})\end{array}$ & $\begin{array}{l}\text { Corrosion } \\
\text { Current }(A)\end{array}$ & $\begin{array}{l}\text { Corrosion Current } \\
\text { Density }\left(\mathrm{A} / \mathrm{cm}^{2}\right)\end{array}$ & $\begin{array}{l}\text { Corrosion } \\
\text { Potential (V) }\end{array}$ & $\begin{array}{c}\text { Polarization } \\
\text { Resistance, } \\
\text { Rp }(\Omega)\end{array}$ & $\begin{array}{c}\text { Cathodic Tafel } \\
\text { Slope, Bc } \\
\text { (V/dec) }\end{array}$ & $\begin{array}{c}\text { Anodic Tafel } \\
\text { Slope, Ba } \\
\text { (V/dec) }\end{array}$ \\
\hline A & 0 & 2.898 & 3.42E-04 & 2.69E-04 & -0.273 & 75.11 & -7.921 & 2.729 \\
\hline B & 0.25 & 5.156 & $6.09 \mathrm{E}-04$ & 4.79E-04 & -0.290 & 42.21 & -8.187 & 2.815 \\
\hline C & 0.5 & 11.300 & 1.33E-03 & $1.05 \mathrm{E}-03$ & -0.284 & 19.26 & -8.703 & -0.154 \\
\hline D & 0.75 & 9.114 & $1.08 \mathrm{E}-03$ & 8.47E-04 & -0.307 & 38.02 & -9.125 & 12.930 \\
\hline E & 1 & 8.818 & 1.04E-03 & $8.20 \mathrm{E}-04$ & -0.296 & 42.53 & -8.825 & 5.787 \\
\hline$F$ & 1.25 & 7.702 & $9.09 \mathrm{E}-04$ & 7.16E-04 & -0.340 & 52.79 & -10.140 & 11.160 \\
\hline G & 1.5 & 6.860 & $8.10 \mathrm{E}-04$ & 6.38E-04 & -0.254 & 66.49 & -8.472 & 8.966 \\
\hline $\mathrm{H}$ & 1.75 & 5.053 & $5.97 \mathrm{E}-04$ & 4.70E-04 & -0.266 & 83.01 & -9.144 & 6.968 \\
\hline
\end{tabular}


where extensive intergranular cracks and micro and macro corrosion pits in the region of the cracks due to the combined electrochemical action of $\mathrm{SO}_{4}{ }^{2-}$ and $\mathrm{Cl}$ - ions. The annealed alloy [Fig. 5(c)] did not experience intergranular corrosion but well defined corrosion pits can be observed. These observations are the product of different phase transformations in the metallurgical structure of 2101ST resulting from the heat treatment processes. Results from electrochemical test showed that ASR2101ST had the lowest corrosion rate however it appears A2101ST was less susceptible to localized corrosion reactions. The morphological damage of ASR2101ST [Fig. 6(a)] is quite extensive compared to Fig. 5(a); intergranular cracks and propagated corrosion pits are clearly visible in addition to the ferrite and austenite phases which can be seen on the alloy. Compared to Fig. 6(b) and (c) the morphological deterioration in Fig. 6(a) seems quite superficial as the degree of localized corrosion deteriorations on the quenched and annealed duplex alloy are quite deeper signifying the detrimental effect of heat treatment on 2101ST.

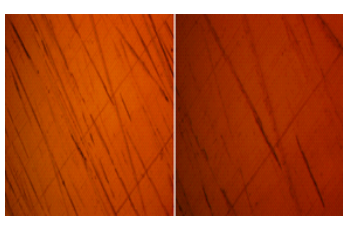

(a)

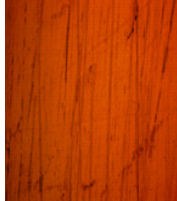

(b)

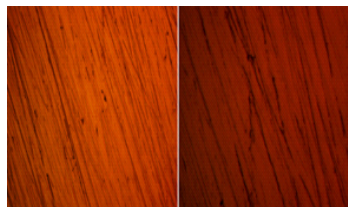

(c)

Fig. 4. Optical images (mag. $x 40$ and $\times 100$ ) of (a) ASR2101ST, (b) Q2101ST and (c) A2101ST before corrosion

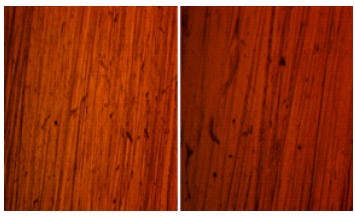

(a)

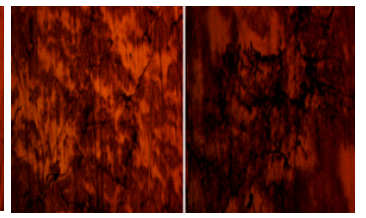

(b)

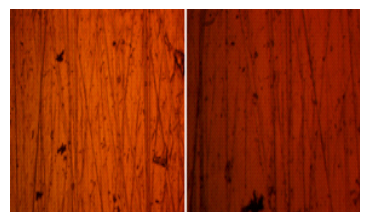

(c)

Fig. 5. Optical images (mag. $x 40$ and $x 100$ ) of (a) ASR2101ST, (b) Q2101ST and (c) A2101ST after corrosion in $2 \mathrm{M} \mathrm{H}_{2} \mathrm{SO}_{4}$ solution

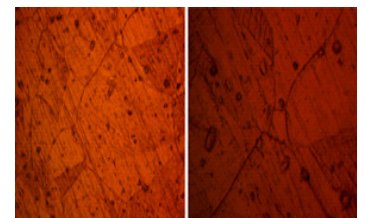

(a)

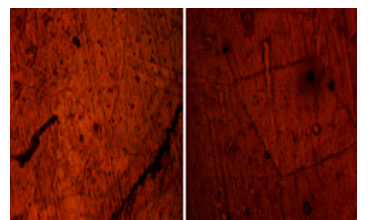

(b)

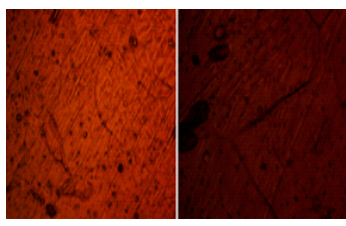

(c)

Fig. 6. Optical images (mag. $x 40$ and $x 100$ ) of (a) ASR2101ST, (b) Q2101ST and (c) A2101ST after corrosion in $2 \mathrm{M}$ $\mathrm{H}_{2} \mathrm{SO}_{4} / 1.25 \% \mathrm{NaCl}$ solution

\section{Open circuit potential measurement (OCP)}

The thermodynamic stability of ASR2101ST, Q2101ST and A2101ST duplex alloys in $2 \mathrm{M} \mathrm{H}_{2} \mathrm{SO}_{4}$, $2 \mathrm{M} \mathrm{H}_{2} \mathrm{SO}_{4} / 0.25 \% \mathrm{NaCl}$ and $2 \mathrm{M} \mathrm{H}_{2} \mathrm{SO}_{4} / 1.75 \% \mathrm{NaCl}$ are shown from Fig. 7(a) to 7 (c). The variation of OCP values versus exposure time for the duplex alloys as shown in the figures indicates that none of the alloys with the exception of Q2101ST in $2 \mathrm{M}$ $\mathrm{H}_{2} \mathrm{SO}_{4}$ [Fig. 7(a)] achieved relative stability for the $2000 \mathrm{~s}$ of exposure time. Q2101ST shifted to -0.300 $\mathrm{V}$ at $100 \mathrm{~s}$ due to instantaneous formation of the passive film, thereafter in decline progressively to $-0.305 \mathrm{~V}$ at $600 \mathrm{~s}$ due to breakdown of the passive film, probably due to localized corrosion reactions in the presence of $\mathrm{SO}_{4}{ }^{2-}$ ions. Beyond $600 \mathrm{~s}$, the OCP value of Q2101ST was relatively stable till 2000 s. ASR2101ST and A2101ST in Fig. 7(a) experienced brief decrease in OCP for the first 200 $\mathrm{s}$ and $100 \mathrm{~s}(-0.308 \mathrm{~V}$ and $-0.281 \mathrm{~V})$ due to active corrosion reactions on the alloy surface, after which a progressive increase in OCP was observed due to formation of the passive protective film on the alloys surfaces. Similar phenomenon was observed for ASR2101ST, Q2101ST and A2101ST in Fig. 7(b), however A2101ST after declining to $-0.278 \mathrm{~V}$ (100 s) was relatively stable till $1050 \mathrm{~s}(-0.277 \mathrm{~V})$ due to active-passive corrosion behavior resulting instantaneous breakdown and repassivation of the oxide film occurring on the alloy surface; after which the OCP value progressively increased to $2000 \mathrm{~s}$. It must be noted that at rest potential A2101ST is the most corrosion resistant duplex alloy despite the contrary from potentiodynamic polarization and optical microscopy where ASR2101ST was 
determined to be the most susceptible to corrosion. The significant variation in OCP between A2101ST and other duplex alloys is due to the strength of its passive oxide layer which tends to be more resistant to corrosion compared to ASR2101ST and A2101ST. In $2 \mathrm{M} \mathrm{H}_{2} \mathrm{SO}_{4} / 1.75 \% \mathrm{NaCl}$ [Fig. 7 (c)], the OCP values of A2101ST was the most electronegative till $1850 \mathrm{~s}$ $(-0.251 \mathrm{~V})$ of exposure due to comparatively weaker corrosion resistance compared to ASR2101ST and Q2101ST, however the relative increase in OCP

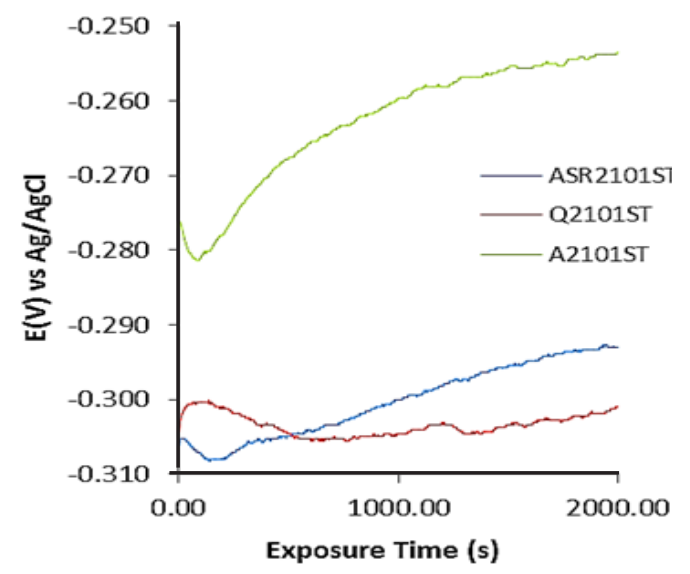

(a) values shows the oxide film on the three duplex alloy specimens is rapidly forming in the presence of $(1.75 \%$ $\mathrm{NaCl}$ ). Observation of the OCP plots in Fig. 7(c) also shows the relatively weak corrosion resistance of Q2101ST. At 250 s (-0.276) the rate of increase in OCP values begins to decrease due to earlier formation of its oxide film which indicates the film is quite thinner compared to ASR2101ST and A2101ST. It eventually overlaps with A2101ST at $1850 \mathrm{~s}$.

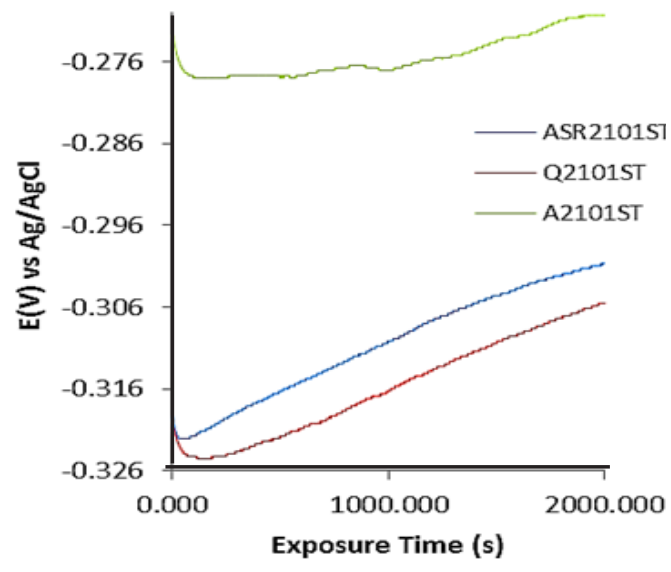

(b)

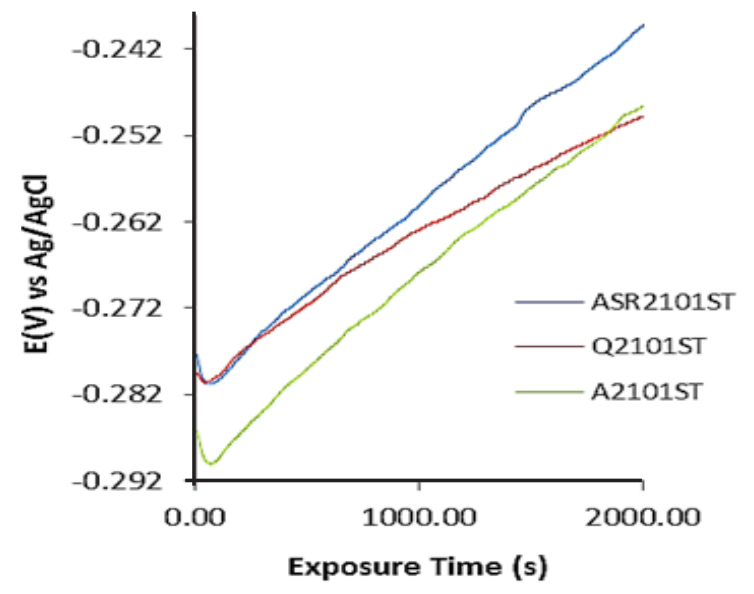

(c)

Fig. 7. Variation of OCP versus exposure time for ASR2101ST, Q2101ST and A2101ST (a) $2 \mathrm{M} \mathrm{H}_{2} \mathrm{SO}_{4}$, (b) $2 \mathrm{M} \mathrm{H}_{2} \mathrm{SO}_{4} / 0.25 \%$ $\mathrm{NaCl}$ and (c) $2 \mathrm{M} \mathrm{H}_{2} \mathrm{SO}_{4} / 1.75 \% \mathrm{NaCl}$

\section{CONCLUSION}

Quenching and annealing heat treatment processes at extreme temperature of $1200^{\circ} \mathrm{C}$ deteriorated the corrosion resistance of 2101 duplex stainless in $2 \mathrm{M} \mathrm{H}_{2} \mathrm{SO}_{4} / 0 \%-1.75 \% \mathrm{NaCl}$ by $36 \%$ and $48 \%$. While the as received duplex steel retained its corrosion resistance and passivation behaviour at all chloride concentrations studied, the quenched and annealed duplex steels lost their passivity. Optical microscopy images showed severely deteriorated morphology with visible intergranular cracks and corrosion pits. 


\section{ACKNOWLEDGEMENT}

The author acknowledges Covenant
University Ota, Ogun State, Nigeria for the sponsorship and provision of research facilities for this project.

\section{REFERENCES}

1. Kai Wang, C.; Sie Chin, T. Materials., 2014, 7(7),5268-5304 (2014). doi:10.3390/ ma7075268.

2. Charles, J. Weld. World., 1995, 36, 43-54.

3. Park, C.J.; Kwon, H.S. Corros. Sci., 2002, 44(12), 2817-2830.

4. Esteves, L.; Cardoso, M.; Lins, V.F.C. Mats. Res., 2018, 12(1). doi.org/10.1590/19805373-mr-2017-0148.

5. Bastos, I.N.; Tavares, S.S.M.; Dalarda, F.; Nogueira, R.P. Scr. Mater., 2007, 57(10), 913-916.

6. Deng, B.; Jiang, Y.; Gong, J.; Zhong, C.; Gao, J.; Li, J. Electrochim. Acta., 2008, 53(16), 5220-5225.
7. Igual Munoz, A.; Garcia Anton, J.; Guinon, J.L.; Perez Herranz, V. Corros. Sci., 2006, 48(12), 4127-4151.

8. Nascimento, A.M do.; lerardi, M.C.F.; Kina, A.Y.; Tavares, S.S.M. Mater. Charact., 2008, 59(12), 1736-1740.

9. Vesna, A., Ivan, S.; Bruno, Z.; Franjo, I. Int. J. Elect. Sci., 2013, 8, 12476 -12486.

10. Alvarez-Armas, I.; Degallaix-Moreuil, S. Duplex Stainless Steels, Wiley; Hoboken, NJ, USA, 2009. doi.org/10.1002/9781118557990. fmatter.

11. Lo, K.H.; Shek, C.H.; Lai, J.K.L. Mater. Sci. Eng. $R$ Rep., 2009, 65(4-6), 39-104. doi: 10.1016/j.mser.2009.03.001. 